\title{
Descrevendo processos de formação de sinais em Libras em uma variedade de Belém do Pará
}

\author{
Describing processes of formation of signs in Libras in a \\ linguistic variety of Belém of Pará
}

\author{
Sindy Rayane de Souza Ferreira* \\ Marília de Nazaré de Oliveira Ferreira**
}

\begin{abstract}
RESUMO: Este trabalho discute questões da Morfologia de Libras, a qual estuda a estrutura interna dos sinais e as regras que determinam a formação desses sinais. Alguns estudos sobre a estrutura morfológica e lexical das línguas de sinais constataram que a Libras apresenta um considerável número de processos que formam sinais, dentre as quais estão a derivação, a composição, a incorporação de numeral e a incorporação da negação. A partir do tratamento dado por Ferreira-Brito (1995), Quadros e Karnopp (2004) e Felipe (2006) aos processos formadores de sinais em Libras, o presente trabalho descreve a ocorrência de tais processos em sinais da variedade de Libras de Belém do Pará.
\end{abstract}

PALAVRAS-CHAVE: Descrição linguística. Morfologia de libras. Formação de sinais.

ABSTRACT: This paper discusses issues of the Morphology of LSB (Brazilian Sign Language) detailed in the internal structure of signs and the determinant rules for the constitution of these signs. Some studies on the morphological and lexical structure of sign languages found out LSB presents a considerable number of processes to form signs, among which are derivation, composition, numeral incorporation and negation incorporation. Considering Ferreira-Brito (1995), Quadros e Karnopp (2004) and Felipe (2006), this work describes the occurrence of such processes in signs of the variety of LIBRAS of Belém of Pará.

KEYWORDS: Linguistic description. Morphology of libras. Formation of signs.

\footnotetext{
* Mestranda em Estudos Linguísticos no Programa de Pós-Graduação em Letras da Universidade Federal do Pará (UFPA) e bolsista Capes. Graduada em Letras - Língua Portuguesa também pela UFPA. E-mail: sindyrayane@hotmail.com.

** Doutora em Linguística pela Universidade Estadual de Campinas (Unicamp). Professora associada do Instituto de Letras e Comunicação, vinculada à Faculdade de Letras, da Universidade Federal do Pará (UFPA). E-mail: marília@ufpa.br.
} 


\section{Introdução}

Apesar de muitas pessoas ainda não conhecerem ou mesmo não aceitarem a Libras como língua, ela é, de fato, a primeira língua da comunidade surda do Brasil. A lei no 10.436, sancionada em 20 de abril de 2002, e o decreto no 5.626, de 22 de dezembro de 2005, declaram ser a Libras uma língua genuína, com todas as características pertencentes aos universais e níveis linguísticos.

As línguas de sinais, assim como as línguas orais, também apresentam todas as propriedades inerentes às línguas humanas. Elas são flexíveis, pois podem fazer referência a qualquer tempo ou coisa; são arbitrárias, porque em muitos sinais não há nenhuma explicação clara para a relação entre as suas formas e os seus respectivos significados (é o caso do sinal BRINCAR - não há como prever o seu significado a partir da forma):

Figura 1 - Sinal BRINCAR

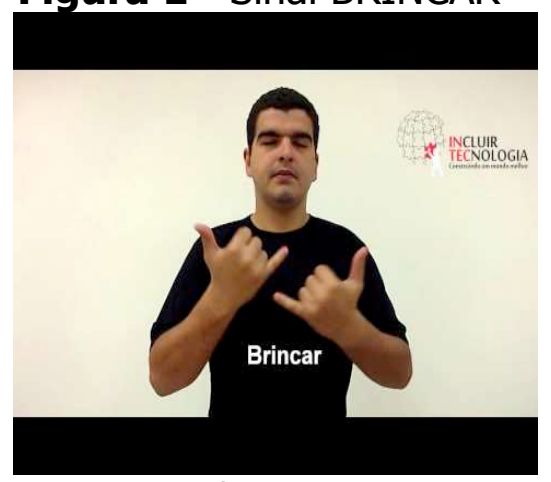

Fonte: Google imagens.

Também são descontínuas, já que sinais como AMAR e SÁBADO se diferem minimamente na forma (somente no parâmetro locação), mas diferem significativamente no sentido: 
Figura 2 - Sinal AMAR

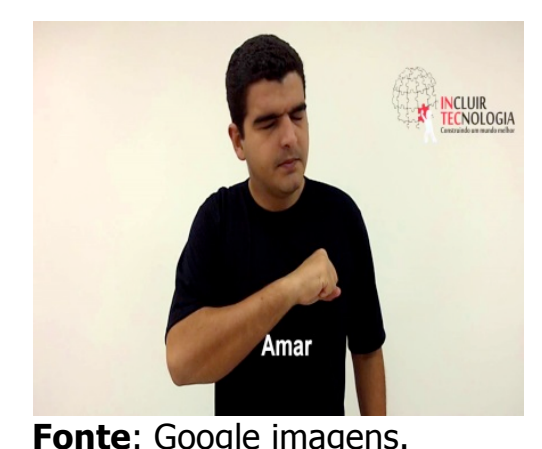

Fonte: Google imagens.

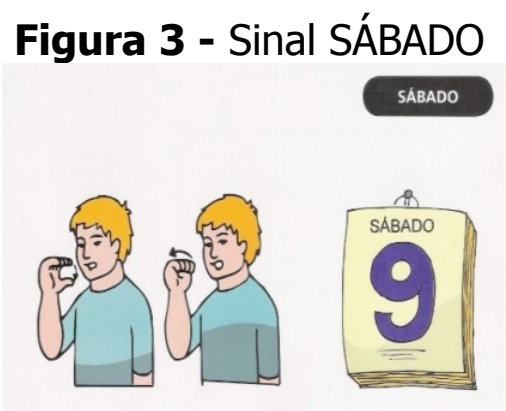

Fonte: Google imagens.

As línguas de sinais apresentam produtividade, pois inúmeros enunciados podem ser criados a partir das regras dessas línguas; possuem dupla articulação, visto que estão organizadas em dois estratos: as unidades formacionais (que correspondem às unidades de som nas línguas orais) e as suas combinações simultâneas ${ }^{1}$; tais línguas apresentam padrão, pois os itens lexicais são organizados de acordo com regras internalizadas pelos falantes dessas línguas; e, por fim, elas possuem dependência estrutural, visto que são constituídas de estruturas dependentes conhecidas e utilizadas (intuitivamente) pelos seus usuários. Desta forma, as línguas de sinais são línguas naturais. Quadros e Karnopp (2004, p. 30) dissertam a respeito disso:

\footnotetext{
${ }^{1}$ É importante destacar que nas línguas orais os fonemas são realizados um de cada vez, ou seja, linearmente; já nas línguas de sinais, eles são realizados todos ao mesmo tempo, isto é, simultaneamente.
} 
As línguas de sinais são consideradas línguas naturais e, consequentemente, compartilham uma série de características que Ihes atribui caráter específico e as distingue dos demais sistemas de comunicação. [...] São, portanto, consideradas pela linguística [...] como um sistema linguístico legítimo e não como um problema do surdo ou como uma patologia da linguagem.

Somente a partir de 1960, com os estudos de Wiliam Stokoe, as línguas de sinais começaram também a ser entendidas como línguas genuínas e os sinais vistos como símbolos abstratos com complexa estrutura.

As línguas de sinais possuem estruturas gramaticais que confirmam sua naturalidade. A Libras, por exemplo, apresenta estruturas frasais complexas, conforme exposto por Castro e Carvalho (2011, p. 25):

\begin{abstract}
Podemos afirmar que a Língua Brasileira de Sinais é uma língua cuja estrutura é, fortemente, orientada por objetivos visuais principais relacionados a elementos visuais complementares. Tal orientação visual pela imagem do pensamento leva, naturalmente, a uma estruturação diferenciada das frases construídas em Libras, além da adaptação de cada sinal segundo o contexto visual. Em alguns casos, você criará frases numa estrutura onde a ordem do sujeito (S), do verbo $(\mathrm{V})$ e do objeto $(\mathrm{O})$ poderá ser SVO, VSO ou OVS, que são estruturas predominantes do português, mas na maioria dos casos, você criará frases numa estrutura tópico-comentário, estrutura predominante em Libras.
\end{abstract}

As línguas de sinais podem ser comparáveis a quaisquer línguas orais tanto em relação à sua complexidade quanto à sua expressividade. Todas as características vistas acima mostram e confirmam que a Libras e todas as línguas de sinais são línguas naturais e possuidoras dos universais linguísticos pertencentes às línguas humanas.

\title{
Morfologia geral e morfologia em libras
}

A morfologia é a parte da linguística que estuda a estrutura interna das palavras, observando-as isoladamente, ou seja, sem estarem estas participando de uma frase ou enunciado. Ela também investiga os processos que criam 
novas palavras nas línguas. De acordo com Dubois et al. (1989, p. 421), em linguística moderna:

\begin{abstract}
A morfologia é a descrição das regras que regem a estrutura interna das palavras, isto é, as regras de combinação entre os morfemasraízes para construir 'palavras' (regras de formação das palavras) e a descrição das formas diversas que tomam essas palavras conforme a categoria de número, gênero, tempo, pessoa [...].
\end{abstract}

Embora a definição de palavra seja um tanto controversa em Linguística, Figueiredo Silva (2009, p. 11), define palavra como "um conjunto de um ou mais morfemas com som e sentido, que se comporta como uma forma livre ou como uma forma dependente na língua". Já o morfema é definido como "a menor unidade de som e sentido na língua".

Há morfemas de diferentes tipos que são classificados de acordo com seu comportamento. Alguns morfemas se comportam como formas presas na língua, aparecendo em ordem fixa junto com outros elementos; comportam-se como formas livres, aparecendo sozinhos como um enunciado completo; ou como formas dependentes, aparecendo sempre ligados a palavras, mas com autonomia em relação a elas. Quadros e Karnopp (2004) afirmam que certos morfemas constituem palavras por si só (morfemas livres), mas outros nunca formam palavras (morfemas presos).

Os estudos tradicionais de morfologia sempre levaram em conta somente as línguas orais, tanto que os conceitos de palavra e morfema mencionam o termo 'som'. As línguas de sinais, mais uma vez, não estavam sendo levadas em consideração no âmbito dos estudos linguísticos. No entanto, sabe-se hoje que a Língua Brasileira de Sinais e todas as línguas de sinais existentes no mundo são constituídas de morfologia e de outros níveis linguísticos.

A morfologia de Libras, bem como a de todas as línguas de sinais, semelhante à morfologia das línguas orais, "é o estudo da estrutura interna das 
palavras ou dos sinais, assim como das regras que determinam a formação das palavras $^{2 \prime \prime}$ (QUADROS; KARNOPP, 2004, p. 86).

Existem, pelo menos, dois tipos de morfologia nas línguas do mundo: a sequencial e a simultânea. A morfologia sequencial é aquela em que os morfemas são combinados sequencialmente, ou seja, um de cada vez (esse tipo de morfologia é mais comumente encontrada nas línguas orais). Já a morfologia simultânea, como o próprio nome indica, é aquela em que os morfemas são combinados simultaneamente, isto é, todos ao mesmo tempo (essa morfologia é mais comum nas línguas de sinais).

A morfologia sequencial nas línguas de sinais não é muito estudada por pesquisadores, pois a ocorrência dessa morfologia nessas línguas é algo raro. A escassez da afixação sequencial nas línguas gestuais ocorre por conta de dois fatores, conforme mostra Quadros, Pizzio e Rezende (2009, p. 27):

\footnotetext{
Primeiramente, como esses afixos emergem por meio do processo de gramaticalização de itens lexicais livres, eles levam tempo para se desenvolverem na língua. Em segundo lugar, eles passam por vários estágios intermediários nesse processo e alguns deles podem coexistir na língua durante certo período, fazendo com que seja difícil identificá-los como tal.
}

Ainda segundo a supracitada autora, além das estruturas sequenciais se diferenciarem das simultâneas no modo como os morfemas são afixados, também se diferem em outras características, como mostra o quadro baixo, retirado de Aronoff et al. (2005 apud QUADROS; PIZZIO; REZENDE, 2009, p. 31):

\footnotetext{
2 Segundo Felipe (2006, p. 02), os sinais, nas línguas visual-espaciais, correspondem às palavras nas línguas oral-auditivas, sendo também formados por morfemas (unidades mínimas de significado). Assim, os sinais podem ser chamados de palavras ou mesmo de sinais.
} 
Quadro 1 - Morfologia Simultânea vs. Morfologia Sequencial

\begin{tabular}{|c|c|}
\hline MORFOLOGIA SIMULTÂNEA & MORFOLOGIA SEQUENCIAL \\
\hline É universal entre as línguas de sinais & É específica para cada língua de sinais \\
\hline Está relacionada à cognição espacial & NÃO está relacionada à cognição espacial \\
\hline É motivada & É arbitrária \\
\hline É relacionada a palavras livres & É gramaticalizada de palavras livres \\
\hline É coerente semanticamente & É MENOS coerente semanticamente \\
\hline É produtiva & Tem produtividade limitada \\
\hline Tem menos variação individual & Tem variação individual considerável \\
\hline
\end{tabular}

Fonte: Do autor.

A morfologia sequencial ainda não foi identificada na Língua Brasileira de Sinais, e nem há estudos neste campo morfológico. Por isso, afirma-se que a morfologia comum nessa língua é a simultânea.

\section{Processos de formação de sinais em Libras}

Todas as línguas existentes no mundo, independente de sua modalidade linguística, apresentam processos responsáveis pela criação de novas palavras nessas línguas. Em Libras não é diferente. Ela possui um léxico bem vasto e um sistema de criação de novos sinais em que os morfemas são combinados. Tal combinação se dá entre os morfemas lexicais e os morfemas gramaticais ou derivacionais, conforme mostra Felipe (2006, p. 201):

\footnotetext{
Nos estudos sobre os processos de formação de palavras [composição, aglutinação, justaposição e derivação], as línguas são sempre apresentadas em relação aos seus morfemas lexicais (raízes/radicais) que se prendem a morfemas gramaticais formantes (desinências e vogais temáticas) e/ou a derivacionais (afixos e clíticos).
} 
A autora afirma que os cinco parâmetros das línguas de sinais expressam morfemas por meio de algumas configurações de mão, alguns movimentos, algumas alterações na frequência do movimento, alguns pontos de articulação na estrutura morfológica e alguma expressão facial ou movimento de cabeça concomitante ao sinal. Através das alterações nas combinações desses morfemas, os itens lexicais das línguas de sinais são formados. Tais morfemas podem ser: morfemas lexicais, podendo ser uma raiz ou um radical $\left(\mathrm{M}^{3}\right)$; morfemas derivacionais, que podem ser um afixo (alterações em $\mathrm{M} \mathrm{e} \mathrm{CM}^{4}$ ); ou morfemas gramaticais, caracterizando uma desinência, ou seja, uma marca de concordância número pessoal (DIR ${ }^{5}$ ) ou de gênero (CM).

A Língua Brasileira de Sinais apresenta processos derivacionais, os quais são processos formadores de novas palavras a partir de palavras já existentes na língua. Entre eles estão derivação, composição e incorporação, que são processos bem produtivos em Libras.

\section{Derivação}

Nas línguas de sinais, o processo de derivação é aquele que deriva nomes de verbos ou verbos de nomes. Em Libras, os nomes derivam de verbos, caracterizando um processo chamado de nominalização. Quadros e Karnopp (2004), seguindo a proposta de Supalla e Newport (1978) para a Língua de Sinais Americana (ASL), argumentam que a Língua Brasileira de Sinais pode derivar nomes de verbos por meio da mudança no tipo de movimento. $O$ movimento dos nomes repete e o movimento dos verbos encurta, como em SENTAR (verbo) e CADEIRA (substantivo):

\footnotetext{
3 Movimento.

${ }^{4}$ Configuração de Mão.

${ }^{5}$ Direcionalidade da Mão.
} 
Figura 4 - Sinais SENTAR e CADEIRA

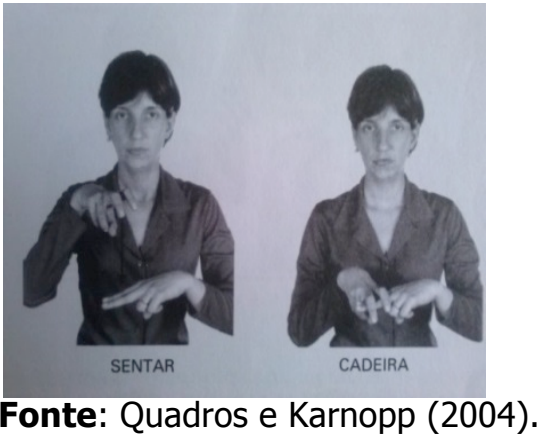

No exemplo acima, é possível ver que o sinal para o verbo SENTAR tem um movimento encurtado. Para formar o sinal CADEIRA, que é substantivo, foi necessário a repetição do movimento. A configuração de mão e a locação são as mesmas nos pares de sinais.

Felipe (2006) propõe a ocorrência do processo de derivação zero como tipo de derivação presente em Libras. Nesse processo, itens lexicais são diferenciados somente a partir da sua função no contexto linguístico onde estão inseridos. Isto quer dizer que dependerá do contexto linguístico identificar se o sinal corresponde a um verbo ou a um nome. Exemplo: DIRIGIR e CARRO.

Figura 5 - Sinal DIRIGIR ou CARRO

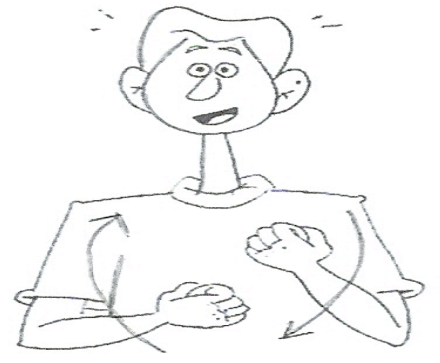

Fonte: Google imagens.

O sinal DIRIGIR é utilizado em frases como: EU DIRIGIR (verbo) CAMINHÃO MEU PAI. Já o sinal CARRO é utilizado em frases como: EU COMPRAR CARRO (substantivo) VELHO. Esses itens lexicais são sinalizados da mesma forma (com a mesma configuração de mão, a mesma locação e o mesmo movimento). Ao serem realizados, o que vai diferenciá-los (se é o 
substantivo CARRO ou o verbo DIRIGIR) é o contexto de frase em que estarão sendo usados.

\section{Composição}

O processo de composição é bem produtivo na Língua Brasileira de Sinais, sendo formador de muitos sinais nessa língua. De acordo com Felipe (2006), a composição pode se realizar de três maneiras em Libras:

1) Pela justaposição de dois itens lexicais - como em ALMOÇAR, formado pela junção de MEIO-DIA com COMER.

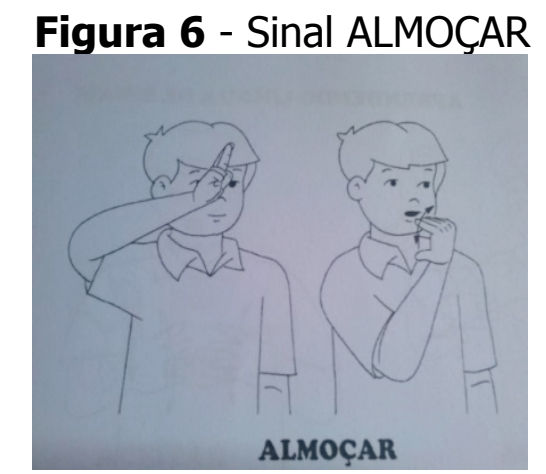

Fonte: Quadros e Karnopp (2004).

2) Pela justaposição de um classificador com um item lexical - como em FORMIGA, formado pela junção de INSETO com COISA PEQUENA [classificador]

Figura 7 - Sinal FORMIGA

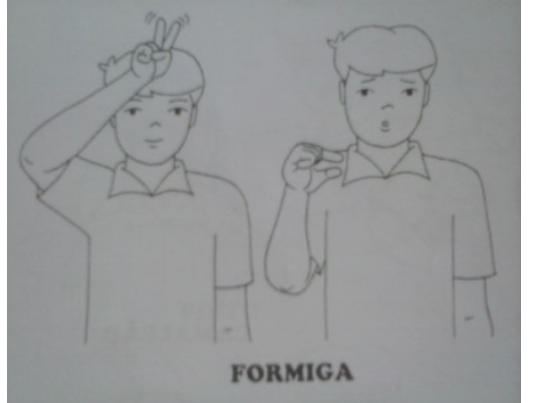

Fonte: Quadros e Karnopp (2004). 
3) Pela justaposição da datilologia da palavra em português com o sinal que representa a ação realizada pelo substantivo, como, por exemplo, AGULHA ${ }^{6}$, formado pela junção de COSTURAR-COM-AGULHA com A-G-UL-H-A.

Além dessas maneiras de realização do processo de composição em Libras, há ainda três regras morfológicas utilizadas na criação de compostos. Quadros e Karnopp (2004) apontam estas regras:

1) Regra do contato: quando dois sinais ocorrem juntos para formar um sinal composto, o contato do primeiro ou do segundo sinal é mantido. Como exemplo tem-se o sinal composto ESCOLA, formado pelos sinais CASA e ESTUDAR, em que o contato do primeiro e do segundo sinal é mantido no composto.

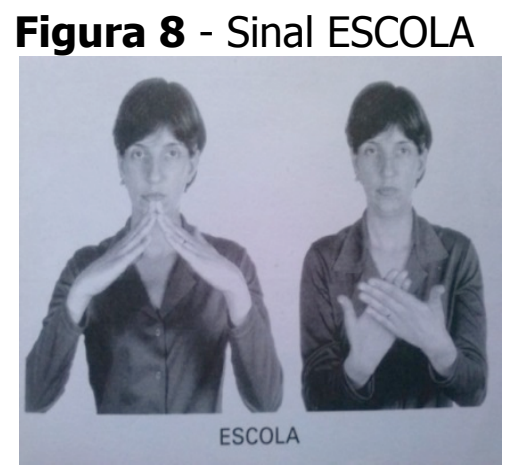

Fonte: Quadros e Karnopp (2004).

2) Regra da sequência única: em compostos, o movimento interno ou a repetição do movimento é eliminada. Por exemplo: os sinais PAI e MÃ ${ }^{7}$, isoladamente, apresentam movimento repetido, mas quando se juntam para formar o sinal composto PAIS, esse movimento é eliminado.

\footnotetext{
${ }^{6} \mathrm{~A}$ imagem que ilustra esse sinal, da forma apresentada por Felipe (2006), não foi encontrada.

${ }^{7}$ Variantes do Rio Grande do Sul.
} 
Figura 9 - Sinal PAIS

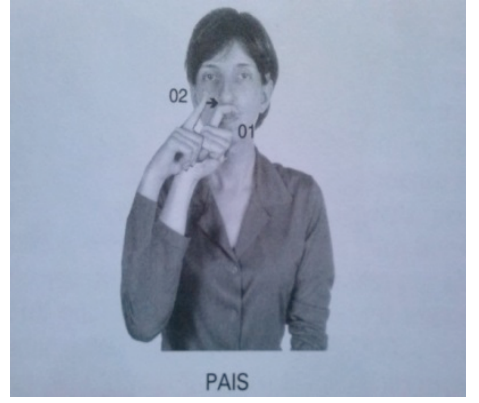

Fonte: Quadros e Karnopp (2004)

3) Regra da antecipação da mão não dominante: esta regra diz que a mão passiva do sinalizador antecipa o segundo sinal no processo de composição. Exemplificando: no sinal composto ACREDITAR (SABER e ESTUDAR), a mão não dominante fica no espaço neutro em frente ao sinalizador com uma configuração de mão que faz parte do composto.

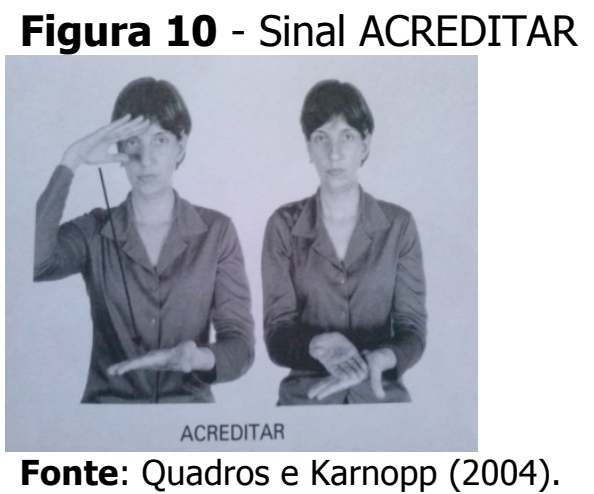

Cada sinal tem um significado próprio quando são realizados isoladamente. Ao se unirem para formar um novo sinal, esses sinais, juntos, passam a ter um novo significado. Na maioria das vezes, tais sinais compostos têm o significado bem distante do significado dos sinais de base. Por isso, é correto afirmar que, no resultado do processo de composição, não há como prever o significado do novo sinal somente observando o significado dos sinais de base (QUADROS; KARNOPP, 2004). 


\section{Incorporação}

Outro processo comum na formação de palavras da Língua Brasileira de Sinais é a incorporação, havendo dois tipos nessa língua: a incorporação de numeral e a incorporação da negação.

Segundo Quadros \& Karnopp (2004), morfemas presos (unidades mínimas com significado que não ocorrem sozinhos) podem se combinar (ou combinar com um morfema livre) para criar novos significados em Libras. Isto ocorre no processo de incorporação de numeral, cuja mudança na configuração de mão (de 1 para 2, para 3 ou para 4) de um sinal pode mudar o número de meses, de dias, de horas, de anos e outros advérbios. Os outros componentes dos sinais permanecem os mesmos. Somente a configuração de mão muda.

Veja o exemplo: UM-MÊS, DOIS-MESES, TRÊS-MESES e QUATRO-MESES

Figura 11 - Sinais UM-MÊS, DOIS-MESES, TRÊS-MESES e QUATRO-MESES

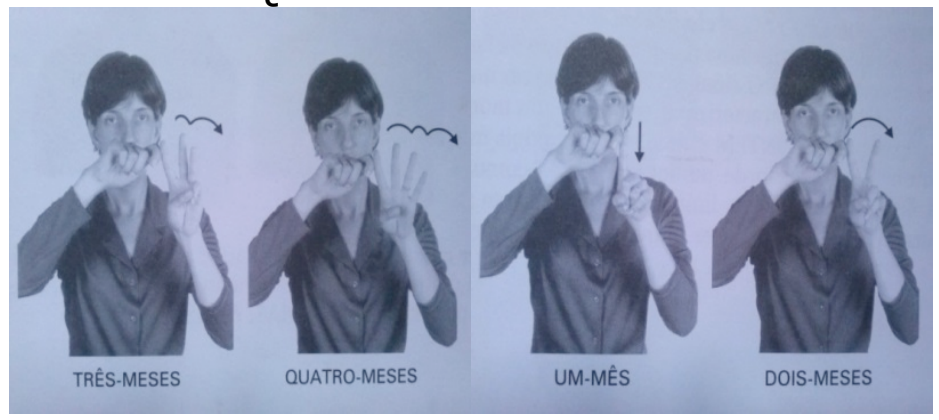

Fonte: Quadros e Karnopp (2004).

Esses sinais são formados por dois morfemas presos: um morfema significa MÊS e abrange a orientação da mão, a locação e as expressões não manuais; e o outro morfema é a configuração de mão, que leva o significado de um numeral. Tais morfemas são realizados concomitantemente, formando o sinal UM-MÊS, DOIS-MESES, TRÊS-MESES ou QUATRO-MESES, dependendo do numeral que é incorporado.

Felipe (2006, p. 204) também confirma a existência do processo de incorporação de numeral, e a respeito dele afirma: "a incorporação do numeral, 
representando os numerais de um até quatro através de configurações de mão, acrescenta à raiz um quantificador". A autora menciona algo que é importante destacar: a configuração de mão para os sinais DIAS, MESES, ANOS OU HORAS pode ser mudada até o número 4 . A partir do número 5 , o numeral é articulado separadamente dos sinais.

O outro processo de incorporação é a incorporação da negação. Nesse processo, o item lexical negado sofre alteração em um dos parâmetros (geralmente no movimento), resultando em sua contraparte negativa (FERREIRA-BRITO, 1995). Para Felipe (2006), essa alteração ocorre da seguinte forma: o sufixo de negação se incorpora à raiz de alguns verbos (que possuem uma raiz com um primeiro movimento), finalizando-os com um movimento contrário, como, por exemplo, o verbo $\operatorname{GOSTAR}^{8}$ e a sua contraparte NÃO-GOSTAR.

Figura 12 - Sinais GOSTAR e NÃO-GOSTAR

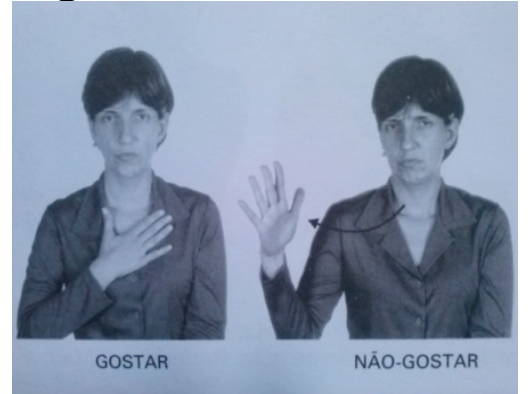

Fonte: Quadros e Karnopp (2004)

Além da incorporação da negação por meio da alteração de um parâmetro, Felipe (2006) e Ferreira-Brito (1995) apontam outra forma de negação: a negação por meio da expressão facial, incorporada ao sinal e sem alteração dos parâmetros. De acordo com Felipe (2006), o infixo de negação se incorpora à raiz de alguns verbos por meio do movimento negativo da cabeça. Essa expressão facial é realizada simultaneamente ao sinal, como no verbo CONHECER e na sua contraparte NÃO-CONHECER.

\footnotetext{
${ }^{8}$ Variante do Rio Grande do Sul.
} 


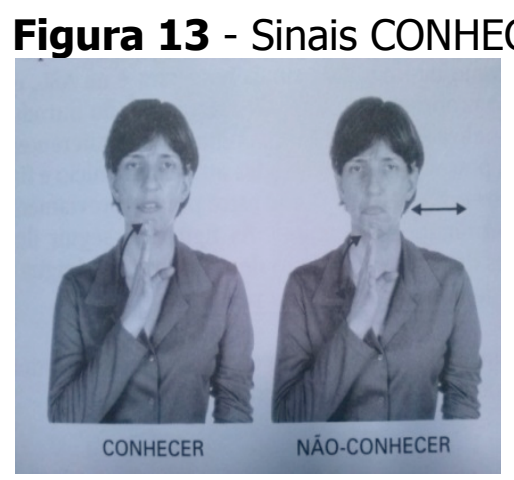

Fonte: Quadros e Karnopp (2004).

\section{Análise de dados}

Com a análise apresentada nesta seção objetiva-se verificar se os processos de formação de sinais descritos anteriormente também ocorrem nos sinais realizados em uma variedade de Libras de Belém do Pará.

Parte da metodologia desta pesquisa envolveu um levantamento de dados para a análise. Foram selecionadas 28 palavras semelhantes aos exemplos expostos por Quadros e Karnopp (2004) e Felipe (2006): verbos e nomes (para verificação da derivação), palavras compostas em Libras (para verificação da composição), advérbios de tempo (para verificação da incorporação de numeral) e verbos com suas contrapartes negativas (para verificação da incorporação da negação). O objetivo dessa seleção foi, principalmente, ilustrar a variedade de Libras da cidade de Belém a partir da verificação da ocorrência dos sinais descritos e sua manifestação de forma similar ou não aos casos descritos pelas autoras mencionadas. É necessário, porém, esclarecer que há coincidência entre alguns sinais de LIBRAS da variedade padrão e aqueles arrolados no presente estudo.

As palavras selecionadas foram apresentadas em uma folha de papel ao informante, que sinalizou cada uma delas. As sinalizações foram registradas em vídeo, mas estão apresentadas neste trabalho por meio de imagens (registros 
estáticos do vídeo) ${ }^{9}$. As imagens reproduzem exatamente a sinalização realizada pelo participante da pesquisa.

A coleta dos dados foi realizada com um informante surdo ${ }^{10}$ na residência do mesmo, em Belém do Pará, no dia 04 de maio de 2014. A entrevista durou cerca de 1 hora. 0 informante é usuário de Libras desde os 7 anos de idade, com idade atual de 21 anos, filho de pais ouvintes, nascido e residente na cidade de Belém (PA).

A seguir, os dados serão apresentados, descritos e analisados de acordo com cada processo de formação de sinais descrito na seção anterior.

\section{Derivação}

A fim de verificar a ocorrência do processo de derivação nos sinais produzidos em Belém, os sinais realizados pelo informante foram: LER, LEITURA, CASAR, CASAMENTO, MORAR, CASA, BRINCAR e BRINCADEIRA.

\section{LER e LEITURA}

Figura 14 - Sinal LER ou LEITURA

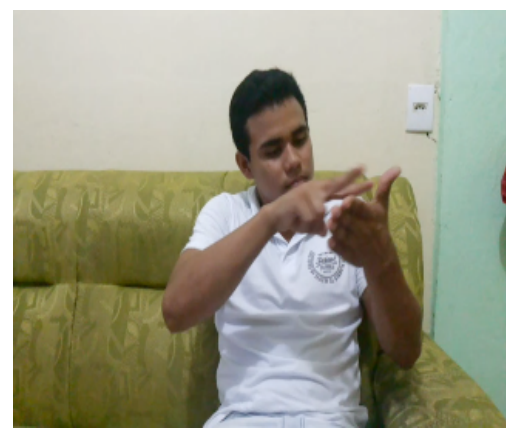

Fonte: Ferreira, 2014.

${ }^{9}$ A utilização das imagens feitas com o informante foi autorizada pelo mesmo.

${ }^{10} \mathrm{O}$ informante tem surdez congênita e profunda. Aprendeu Libras na Escola Felipe Smaldone (especializada para surdos), onde estudou até o $9^{\circ}$ ano. Atualmente cursa o terceiro ano do ensino médio na Escola Estadual Paulino de Brito. Ele é usuário de Libras como L1 e do Português como L2. Não tem implante e não usa nenhum tipo de aparelho auditivo. 
A imagem acima representa a realização dos sinais LER e LEITURA, que são, respectivamente, um verbo e um substantivo. Ambos os sinais são realizados de forma idêntica: a configuração da mão dominante é aberta (com os dedos unidos, exceto o polegar, que fica separado) e a configuração da mão não dominante em forma de " $\mathrm{v";}$ a direcionalidade da palma da mão dominante voltada para um lado e a da mão não dominante voltada para o lado oposto; o local de articulação do sinal é o espaço neutro; e a mão em forma de " $v$ " tem movimento angular.

\section{CASAR E CASAMENTO}

Figura 15 - Sinal CASAR ou CASAMENTO

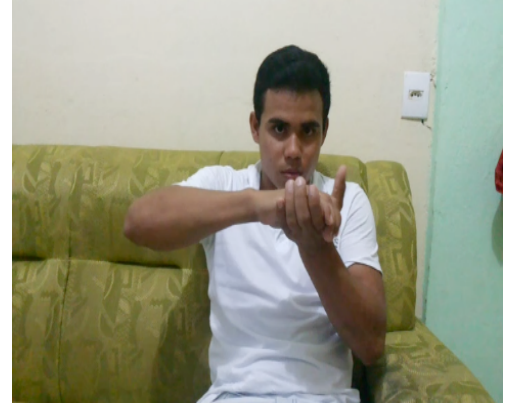

Fonte: Ferreira, 2014.

A imagem acima representa os sinais CASAR e CASAMENTO (também verbo e substantivo, respectivamente), que são produzidos da mesma forma: configuração de ambas as mãos em forma de um " $\mathrm{C}$ " mais aberto; palma da mão dominante direcionada para cima e palma da mão não dominante direcionada para baixo; ponto ou local de articulação é o espaço neutro; e movimento único das mãos se tocando.

MORAR E CASA

Figura 16 - Sinal MORAR ou CASA 


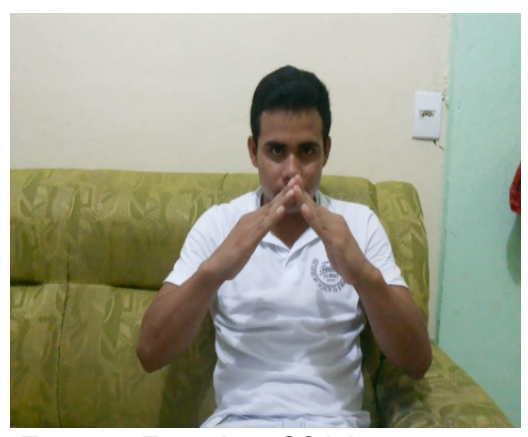

Fonte: Ferreira, 2014.

A imagem acima representa o verbo MORAR e o substantivo CASA, os quais são sinalizados da mesma maneira: as duas mãos têm configuração em forma de "B", tocando-se apenas com as pontas dos dedos; a palma da mão direita é direcionada para o lado esquerdo e a palma da mão esquerda é direcionada para o lado direito; o local de realização dos sinais é o espaço neutro; e ambos os sinais não têm movimento.

\section{BRINCAR e BRINCADEIRA}

Figura 17 - Sinal BRINCAR OU BRINCADEIRA

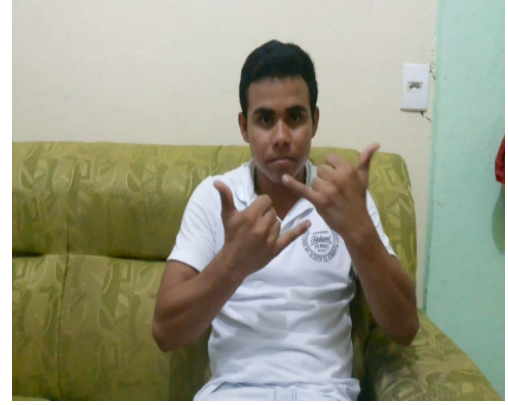

Fonte: Ferreira, 2014.

A imagem acima representa os sinais BRINCAR (verbo) e BRINCADEIRA (substantivo), que também são produzidos de forma idêntica: configuração das mãos em forma de "Y" (próximas uma da outra), com a palma de ambas direcionada para trás; sinais realizados também no espaço neutro; e movimento circular das duas mãos.

Conforme apresentado na seção anterior, Quadros e Karnopp (2004) afirmam que a derivação em Libras ocorre por meio da nominalização, ou seja, nomes são derivados a partir de verbos, de forma que o movimento dos verbos 
encurta e o movimento dos nomes repete. No entanto, o que se observa a partir dos dados coletados é que, à primeira vista, tal proposta não se aplica aos dados apresentados anteriormente, visto que os substantivos não são derivados de seus respectivos verbos. O movimento daqueles não é repetido nem o movimento destes é encurtado.

Os pares de sinais LER e LEITURA, CASAR e CASAMENTO, MORAR e CASA, BRINCAR e BRINCADEIRA são sinalizados de forma idêntica. O que parece distinguir a ocorrência de um nome da ocorrência de um verbo é somente o contexto em que um ou outro aparecem. Tais sinais estão de acordo com a proposta de Felipe (2006), a qual afirma que, em Libras, ocorre um processo denominado derivação zero, no qual itens lexicais são diferenciados somente pela sua função no contexto linguístico onde estão inseridos. Logo, se tal hipótese se confirmar, em pesquisa mais aprofundada, com uma coleta de dados mais densa, envolvendo um maior número de informantes bem como um conjunto mais amplo de dados, essa proposta pode ser aplicada aos pares de sinais citados acima.

\section{Composição}

Para verificar a ocorrência do processo de composição nos sinais produzidos em Belém, os sinais realizados pelo informante foram: IRMÃ, AVÓ, IGREJA E ALFINETE.

\section{IRMÃ}

Figura 18 - Sinal IRMÃ

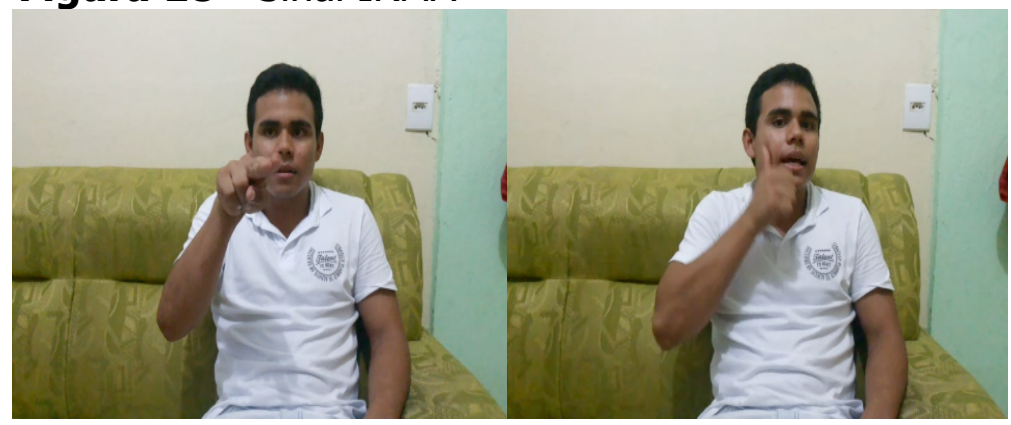

Fonte: Ferreira, 2014. 
O sinal IRMÃ é um sinal composto, formado pela justaposição dos sinais MULHER e IGUAL. Os primeiro e segundo sinais bases são itens lexicais em Libras. A regra morfológica ${ }^{11}$ utilizada na formação do sinal IRMÃ é a regra do contato, pois o contato que há no primeiro sinal (contato entre o polegar e a face) e no segundo sinal (contato entre os dedos indicador e médio) é mantido no sinal composto.

\section{AVÓ}

Figura 19 - Sinal AVÓ

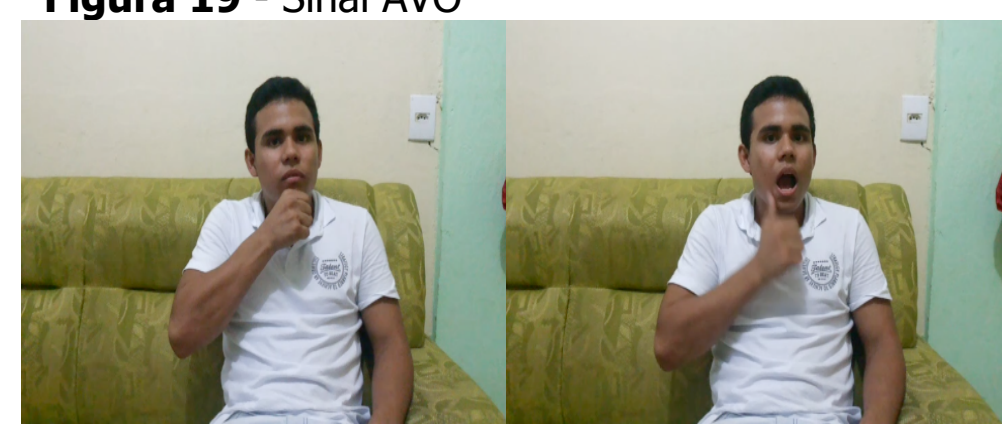

Fonte: Ferreira, 2014.

O sinal AVÓ também é composto, formado pela junção do sinal MULHER com o sinal VELHA. Esses dois sinais bases também são itens lexicais em Libras. A composição do sinal AVÓ apresenta duas regras morfológicas: a regra do contato, visto que há contato nos dois sinais bases (contato entre o polegar e a face, no primeiro sinal, e contato entre a mão e o queixo, no segundo) e esse contato é mantido no composto; e a regra de sequência única, pois a repetição do movimento no sinal VELHA (movimento retilíneo da mão tocando o queixo) é eliminada no composto.

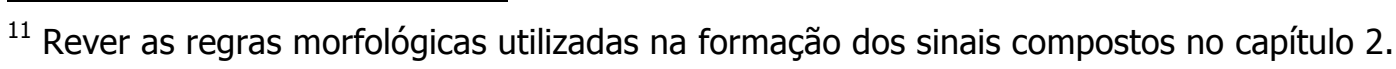




\section{IGREJA}

Figura 20 - Sinal IGREJA

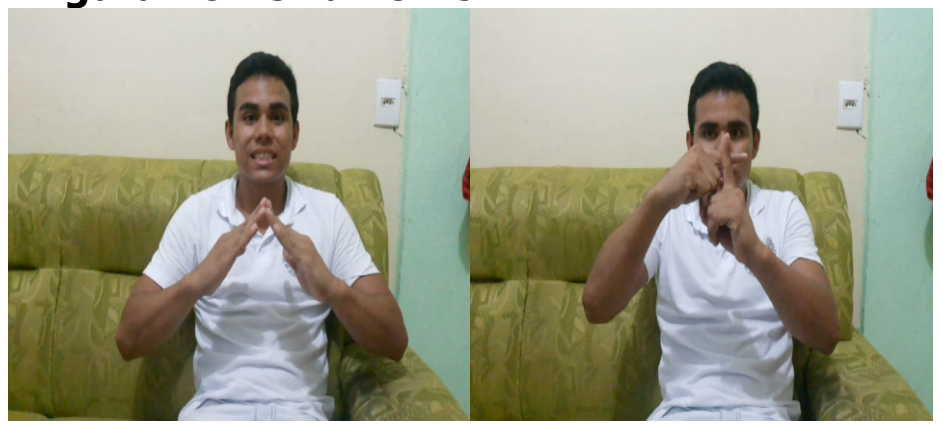

Fonte: Ferreira, 2014.

O sinal IGREJA é um sinal composto, formado pela junção dos itens lexicais CASA e CRUZ. A regra morfológica utilizada na composição do sinal IGREJA é a regra de contato, visto que o contato que há no primeiro sinal (contato entre a ponta dos dedos) e no segundo sinal (contato entre os dedos indicadores) se repete no sinal composto.

\section{ALFINETE}

Figura 21 - Sinal ALFINETE

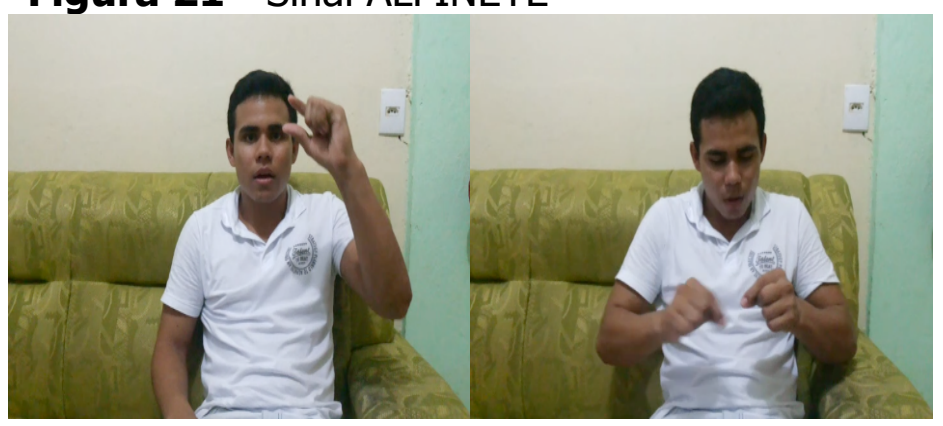

Fonte: Ferreira, 2014.

O sinal ALFINETE é um sinal composto, formado pela justaposição do classificador COISA-PEQUENA com o item lexical COSTURAR (sinal icônico que representa a ação de costurar alguma coisa). Nenhuma das regras morfológicas é utilizada na criação deste composto. 
Segundo Felipe (2006), em Libras, há três maneiras de o processo de composição se realizar: pela junção de dois itens lexicais, pela junção de um classificador com um item lexical e pela junção da datilologia da palavra em português com o sinal que representa a ação realizada pelo substantivo. Partindo da proposta da autora mencionada, pode-se afirmar, em uma primeira análise, que o primeiro tipo de composição é observado nos sinais IRMÃ, AVÓ e IGREJA, uma vez que estes são formados pela justaposição de dois itens lexicais; e que o segundo tipo de composição é observado no sinal ALFINETE, pelo fato de este ser formado pela justaposição de um classificador com um item lexical. Já o terceiro tipo de composição não foi observado em nenhum dos dados.

Quadros e Karnopp (2004) ainda apresentam três regras morfológicas utilizadas na formação dos sinais compostos, conforme visto na seção 3: a regra do contato, a regra da sequência única e a regra da antecipação da mão

não dominante. A primeira regra morfológica é verificada nos sinais IRMÃ, AVÓ e IGREJA, visto que nestes compostos o contato presente nos sinais bases é mantido. A segunda regra pode ser observada no sinal AVÓ, pois a repetição do movimento existente em um dos sinais bases desse composto é eliminada. A terceira regra morfológica é verificada em nenhum dos dados selecionados para esta coleta.

\section{Incorporação}

Para verificação da aplicação do processo de incorporação de numeral e de negação, os sinais produzidos pelo informante foram: UM ANO, DOIS ANOS, TRÊS ANOS, QUATRO ANOS, QUERER, NÃO-QUERER, PODER, NÃO PODER, PRECISAR, NÃO PRECISAR, LEMBRAR e NÃO-LEMBRAR. 


\section{UM ANO}

Figura 22 - Sinal UM ANO

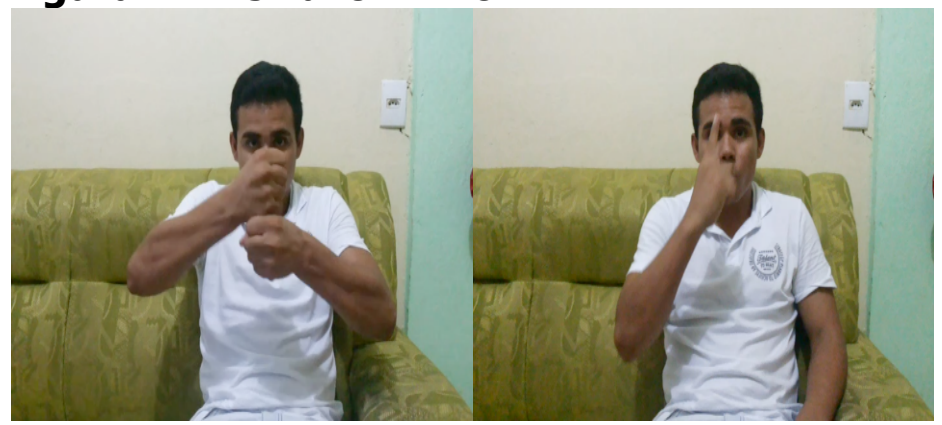

Fonte: Ferreira, 2014.

O advérbio de tempo UM ANO é formado pela combinação de dois morfemas livres: um morfema é o numeral 1 e o outro morfema é o advérbio de tempo ANO. Esses morfemas são realizados linearmente. 0 numeral 1 está determinando a quantidade de anos.

\section{DOIS ANOS}

Figura 23 - Sinal DOIS ANOS

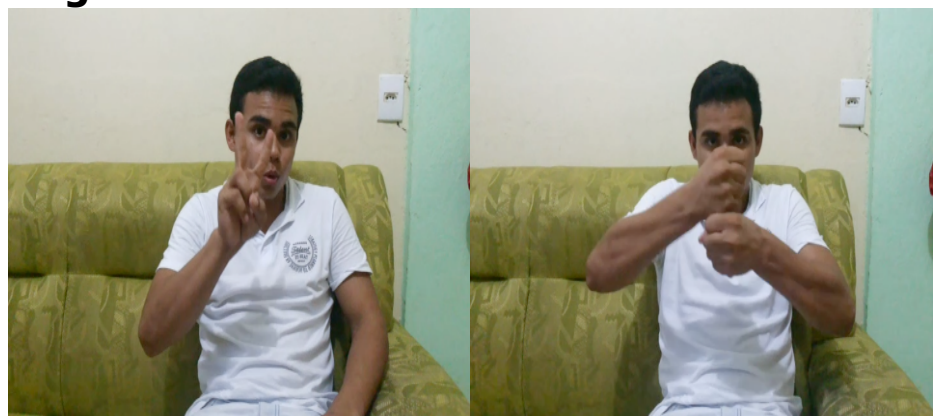

Fonte: Ferreira, 2014.

O advérbio de tempo DOIS ANOS é formado pela combinação de dois morfemas livres: um morfema é o numeral 2 e o outro é o advérbio ANO. Tais morfemas são realizados sequencialmente. 0 numeral 2 está determinando a quantidade de anos. 


\section{TRÊS ANOS}

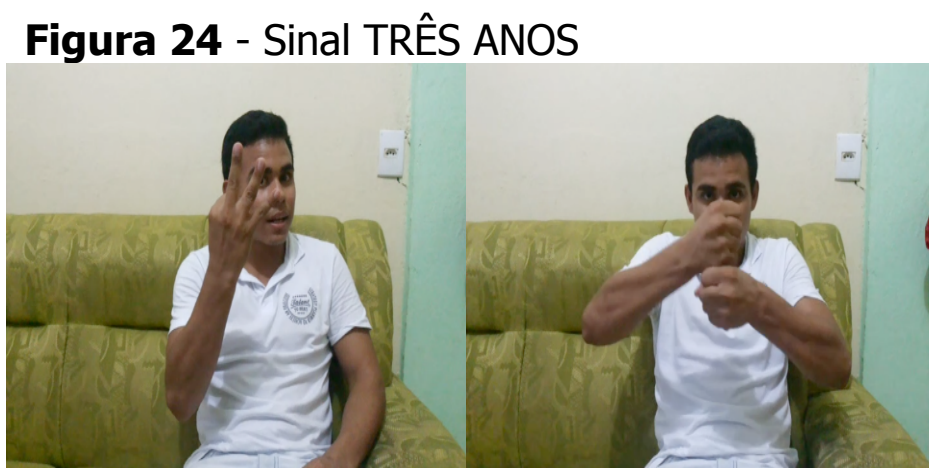

Fonte: Ferreira, 2014.

O advérbio de tempo TRÊS ANOS é também formado pela combinação de dois morfemas livres: o numeral 3 mais o advérbio ANO. Esses morfemas, igualmente aos anteriores, são realizados sequencialmente. 0 numeral 3 está determinando a quantidade de anos.

\section{QUATRO ANOS}

Figura 25 - Sinal QUATRO ANOS

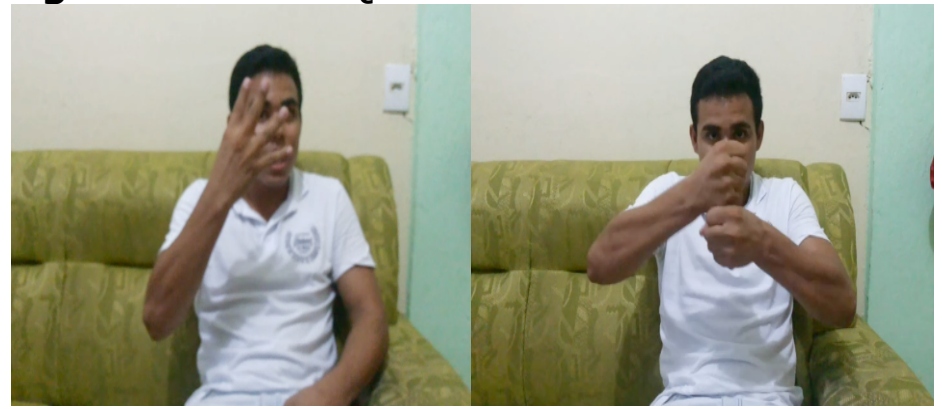

Fonte: Ferreira, 2014.

O advérbio de tempo QUATRO ANOS é formado pela combinação de dois morfemas livres: a combinação do numeral 4 com o advérbio ANO. Ambos os morfemas são realizados linearmente. Da mesma forma que os numerais apresentados anteriormente, o numeral 4 está determinando a quantidade de anos. 
Para Quadros e Karnopp (2004), o processo de incorporação de numeral ocorre em Libras quando morfemas presos se combinam ou combinam com morfemas livres para criar novos significados na língua. As autoras afirmam que os sinais criados por incorporação de numeral (que podem ser sinais com mudanças no número de horas, dias, meses, anos ou outro advérbio) são formados por dois morfemas que se realizam simultaneamente: um morfema representa o advérbio (meses, dias, horas...), abrangendo a orientação da mão, a locação e as expressões não manuais; e o outro morfema é a configuração de mão, que leva o significado de um numeral. 0 morfema que representa o numeral é incorporado ao morfema que representa o advérbio.

Nos dados apresentados anteriormente, percebe-se, à primeira vista, que os advérbios de tempo UM ANO, DOIS ANOS, TRÊS ANOS e QUATRO ANOS são formados pela combinação de dois morfemas livres: um significa o numeral 1 , 2, 3 ou 4; e o outro significa o advérbio ANO. Tais morfemas são realizados sequencialmente. Nestes advérbios, os numerais têm a função de indicar a quantidade de anos. Portanto, o processo de incorporação de numeral não é observado nos dados aqui apresentados, pois não ocorrem de acordo com a proposta de Quadros e Karnopp (2004).

\section{QUERER e NÃO-QUERER}

Figura 26 - Sinal QUERER

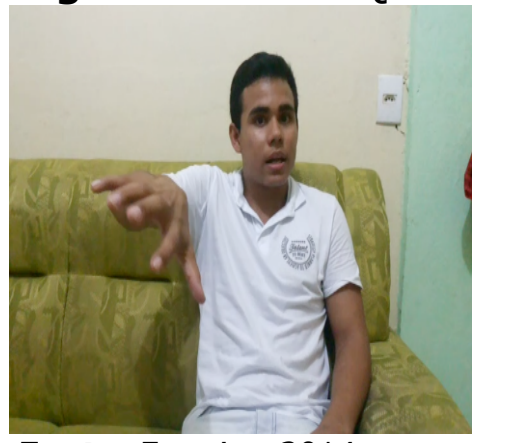

Fonte: Ferreira, 2014. 
Figura 27 - Sinal NÃO-QUERER

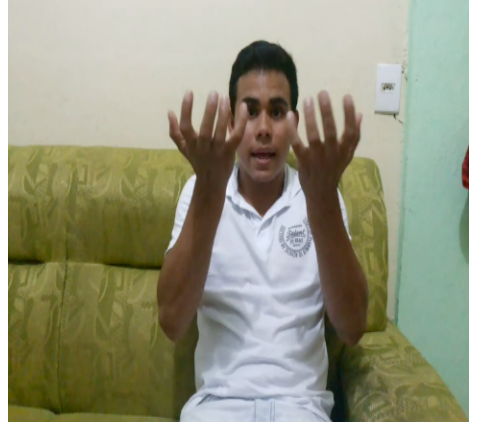

Fonte: Ferreira, 2014.

O oposto do verbo QUERER é o verbo NÃO-QUERER. Esse sinal é formado da seguinte maneira: há a adição de um sufixo de negação à raiz do verbo QUERER, realizando-se pela mudança no movimento do sinal QUERER (realiza-se um movimento contrário); e há a adição de um infixo de negação à raiz do verbo, que ocorre por meio do movimento negativo da cabeça. 0 movimento contrário ao movimento do sinal QUERER e o movimento negativo da cabeça ocorrem ao mesmo tempo, fazendo surgir a contraparte negativa NÃO-QUERER.

\section{PODER E NÃO PODER}

Figura 28 - Sinal NÃO PODER

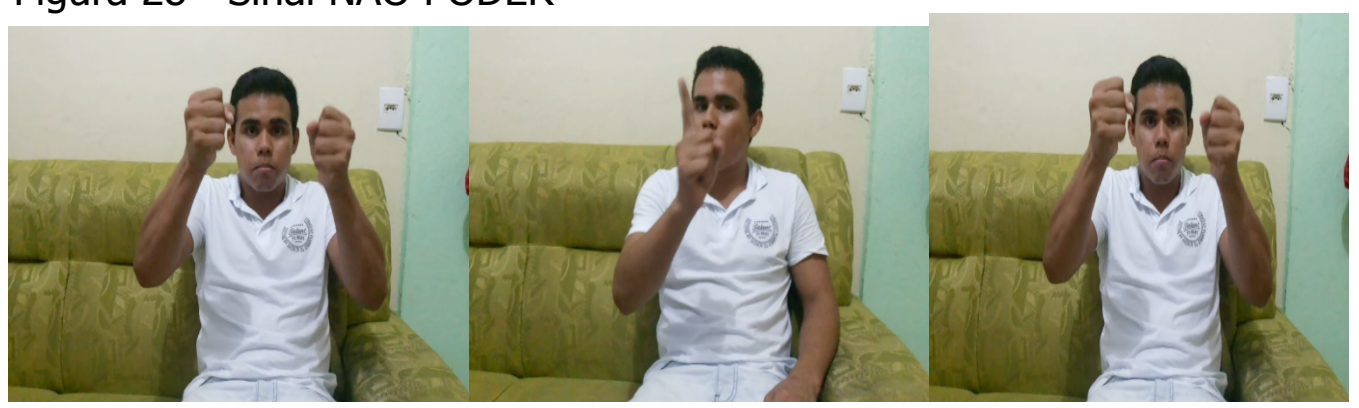

Fonte: Ferreira, 2014.

$O$ verbo que se contrapõem ao verbo PODER é o NÃO PODER. A formação desse último ocorre da seguinte forma: além da adição de um infixo de negação à raiz do verbo PODER (movimento negativo da cabeça), é 
acrescido a este sinal o advérbio de negação NÃO. O movimento negativo da cabeça e o sinal NÃO ocorrem simultaneamente; no entanto, eles ocorrem separados do sinal PODER. É desta maneira que surge a sua contraparte negativa NÃO PODER.

\section{PRECISAR e NÃO PRECISAR}

Figura 29 - Sinal PRECISAR

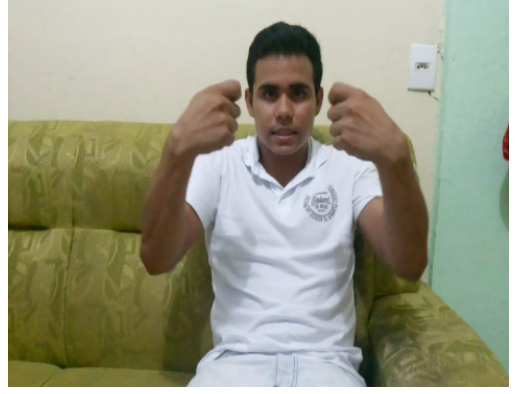

Fonte: Ferreira, 2014.

Figura 30 - Sinal NÃO PRECISAR

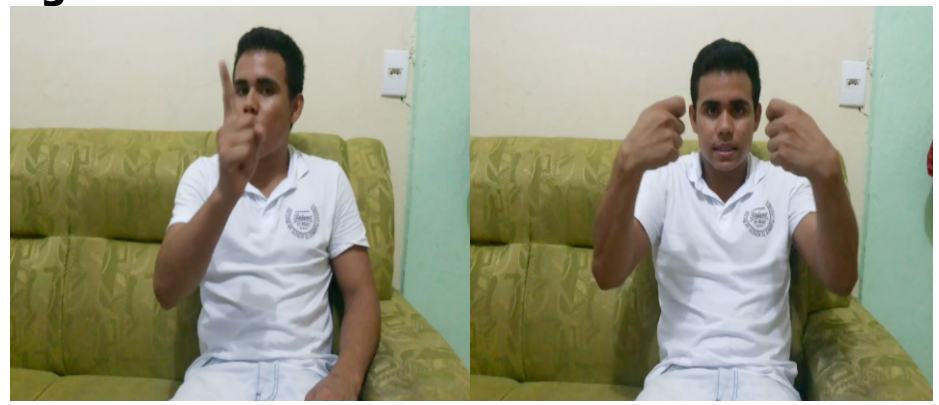

Fonte: Ferreira, 2014.

O verbo NÃO PRECISAR é o oposto do verbo PRECISAR. A formação de NÃO PRECISAR também ocorre por meio da adição de um infixo de negação à raiz do verbo PRECISAR (movimento negativo da cabeça) e do acréscimo do advérbio de negação NÃO a esse verbo. Em tal sinal, o movimento negativo da cabeça e o sinal NÃO também ocorrem concomitantemente; porém, eles ocorrem separados do sinal PRECISAR, surgindo a sua contraparte negativa NÃO PRECISAR. 


\section{LEMBRAR e NÃO-LEMBRAR}

Figura 31 - Sinal LEMBRAR

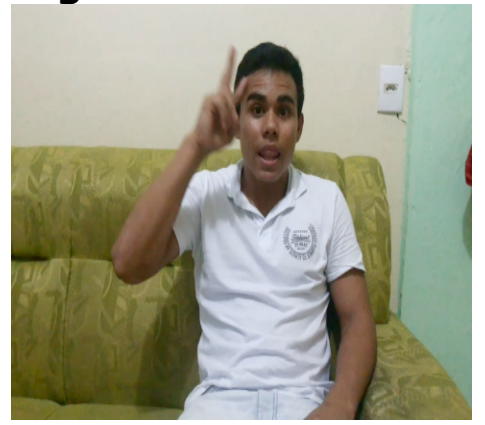

Fonte: Ferreira, 2014.

Figura 32 - Sinal NÃO-LEMBRAR

\section{Fonte: Ferreira, 2014.}

O oposto do verbo LEMBRAR é o verbo NÃO-LEMBRAR. Esse sinal é formado por intermédio da adição de um infixo de negação à raiz do verbo LEMBRAR, que ocorre pelo movimento negativo da cabeça. O movimento negativo da cabeça ocorre junto ao sinal LEMBRAR, surgindo, assim, a sua contraparte negativa NÃO-LEMBRAR.

No processo de incorporação da negação, o item lexical a ser negado, geralmente, sofre alteração no parâmetro movimento, originando a sua contraparte negativa. Felipe (2006) afirma que essa alteração no movimento acontece por meio da incorporação do sufixo de negação à raiz de determinados verbos, que terminam com um movimento oposto. Conforme mostram Ferreira-Brito (1995) e Felipe (2006), outra forma de o item lexical (verbo) ser negado é por intermédio da expressão facial, havendo adição de um movimento negativo da cabeça ao próprio item. 
Com base no estudo do processo de incorporação da negação, à primeira vista, pode-se depreender dos dados expostos anteriormente que:

a) Para a formação do verbo NÃO-QUERER ocorre o processo de incorporação da negação por meio da alteração do parâmetro movimento e por meio da expressão facial, uma vez que tal sinal é formado pela mudança no movimento do verbo QUERER mais o movimento negativo da cabeça (realizados ao mesmo tempo).

b) Para a formação dos verbos NÃO PODER e NÃO PRECISAR observa-se a ocorrência da incorporação da negação pela expressão facial, uma vez que aqueles sinais são formados pelo movimento negativo da cabeça, sendo realizado antes dos sinais PODER e PRECISAR; mas a negação também ocorre nestes verbos por meio de outra forma: o acréscimo do sinal NÃO, realizado junto com o movimento negativo da cabeça.

c) Para a formação do verbo NÃO-LEMBRAR verifica-se a incorporação da negação por intermédio da expressão facial, haja vista que tal sinal é formado pelo movimento negativo da cabeça, realizado juntamente ao sinal LEMBRAR.

A pesquisa apresentada neste artigo é preliminar e não exaure os dados da variedade de Língua Brasileira de Sinais em estudo. Todavia, já há uma indicação de que a formação de alguns sinais nessa variedade se dá de forma distinta daquela descrita por Quadros e Karnopp (2004), Felipe (2006) e Ferreira-Brito (1995), havendo, portanto, necessidade de se aprofundar a pesquisa.

\section{Considerações finais}

O objetivo do presente trabalho foi verificar a ocorrência dos processos de formação de sinais em Libras nos sinais realizados na cidade de Belém do Pará. Partindo dos dados apresentados na seção 4 deste artigo, pode-se considerar que, à primeira vista, na variedade de Libras usada em Belém: 
1) Os sinais coletados para verificação do processo de derivação ocorrem segundo a análise de Felipe (2006), a qual afirma que, em Libras, há um processo chamado de derivação zero, no qual itens lexicais são diferenciados somente pela sua função no contexto linguístico onde estão inseridos. Deste modo, o que distingue a ocorrência de um nome da ocorrência de um verbo é somente o contexto em que um ou outro aparecem;

2) Os sinais coletados para verificação do processo de composição ocorrem conforme as propostas de Felipe (2006) e Quadros e Karnopp (2004). Felipe (2006) argumenta que, em Libras, há três maneiras do processo de composição se realizar: pela junção de dois itens lexicais, pela junção de um classificador com um item lexical e pela junção da datilologia da palavra em português com o sinal que representa a ação realizada pelo substantivo. Já Quadros e Karnopp (2004) apresentam três tipos de regras morfológicas usadas na criação de sinais compostos: a regra do contato, a regra da sequência única e a regra da antecipação da mão não dominante. No entanto, nem todos os tipos de composição nem todas as regras morfológicas foram observados nos dados coletados para esta verificação, o que implica em um estudo mais detalhado, com maior número de informantes e de dados também;

3) Os sinais coletados para verificação do processo de incorporação de numeral não ocorrem de acordo com a proposta de Quadros e Karnopp (2004), que afirmam que o processo de incorporação de numeral ocorre quando morfemas presos se combinam ou combinam com morfemas livres (os quais se realizam simultaneamente) para criar novos significados na língua;

4) Os sinais coletados para verificação do processo de incorporação da negação ocorrem, em parte, segundo as propostas de Felipe (2006) e Ferreira-Brito (1995). A primeira autora diz que, para um item lexical ser negado, este sofre alteração no parâmetro movimento por meio da incorporação do sufixo de negação à raiz de determinados verbos, 
terminando com um movimento oposto. As duas autoras mostram que outra forma de o item lexical ser negado é por intermédio da expressão facial, havendo adição de um movimento negativo da cabeça ao próprio item. Porém, além das formas de negação dos itens lexicais apresentados pelas supracitadas autoras, foi identificada nos dados apresentados no presente artigo outra forma de negação: o acréscimo do sinal NÃO, realizado junto com o movimento negativo da cabeça.

É importante ressaltar que este trabalho constrói hipóteses para a ocorrência dos processos formadores de sinais em uma variedade de Libras de Belém do Pará. Reconhece-se que ainda há muito a ser investigado sobre tais processos. No entanto, espera-se que a discussão aqui apresentada possa contribuir não só para pesquisas futuras, mas também para um maior reconhecimento da Libras, e das línguas de sinais em geral, como língua natural.

\section{Referências}

CASTRO, Alberto Rainha; CARVALHO, Ilza Silva. Comunicação por língua brasileira de sinais: livro básico. 3. ed. Brasília: Senac/DF, 2011.

DUBOIS, Jean et al. Dicionário de lingüística. Traduzido por Frederico Pessoa de Barros et al. São Paulo: Cultrix, 1989.

FELIPE, Tanya Amara. Os processos de formação de palavra na Libras. Estudos Linguísticos: Grupos de Estudos e Subjetividade, Campinas, v. 7, n. 2, p. 200217, jun. 2006.

FERREIRA, Sindy Rayane de Souza. Descrição dos processos de formação de sinais em Libras. 2014. 56 f. Trabalho de Conclusão de Curso (Graduação em Letras) - Faculdade de Letras, Universidade Federal do Pará, Belém (PA), 2014.

FERREIRA-BRITO, Lucinda. Por uma gramática de línguas de sinais. Rio de Janeiro: Tempo Brasileiro, 1995.

FIGUEIREDO SILVA, Maria Cristina. Morfologia. Florianópolis: UFSC, 2009. Disponível em: <http://www.libras.ufsc.br/colecaoLetrasLibras/eixoFormacao 
Basica/morfologia/assets/430/Texto_Base_Morfologia_21_Fev_2009.pdf>. Acesso em: 20 jan. 2014.

QUADROS, Ronice Müller; KARNOPP, Lodenir Becker. Língua de sinais brasileira: estudos linguísticos. Porto Alegre: Artmed, 2004.

QUADROS, Ronice Müller; PIZZIO, Aline Lemos; REZENDE, Patrícia Luíza Ferreira. Língua brasileira de sinais I. Florianópolis: UFSC, 2009. Disponível em: <http://www.libras.ufsc.br/colecaoLetrasLibras/eixoFormacaoEspecifica/linguaB rasileiraDeSinaisI/assets/459/Texto_base.pdf>. Acesso em: 18 mar. 2014.

SUPALLA, Ted; NEWPORT, Elissa. How many seats in a chair? The derivation of nouns and verbs in american sign language. In: SIPLE, P. (ed.). Understanding language through sign language research. New York: Academic Press, 1978. 